\title{
TRANSFORMACIONES EN LAS FAMILIAS: ANÁLISIS CONCEPTUAL Y HECHOS DE LA REALIDAD*
}

\author{
Nancy Piedra Guillén**
}

RESUMEN

Este artículo analiza aspectos conceptuales y cambios fundamentales que se han generado en las familias latinoamericanas. A su vez se compara el caso de Costa Rica con los procesos latinoamericanos, para posteriormente profundizar en la situación particular costarricense. Se invita a reflexionar sobre la necesidad de no quedarse en el estudio de los cambios estructurales, sino más bien profundizar en el estudio de las dinámicas y el tipo de relaciones que se generan a su interior entre las y los integrantes de las familias.

PALABRAS CLAVE: FAMILIA * RELACIONES DE PAREJA * CICLO DE VIDA * RUPTURAS * TRANSFORMACIÓN EN LAS FAMILIAS

\section{ABSTRACT}

This article analyzes conceptual aspects and fundamental changes that have been generated in the Latin American families. The case of Costa Rica is compared with the Latin American processes; later it deepens on Costa Rica's particular situation. An invitation is given to meditate about the necessity of not staying in the study of the structural changes, but rather to deepen in the study of the dynamics and the type of relationships that it is generated to the interior of family and among the members of the families.

KEY WORDS: FAMILY * COUPLE RELATIONSHIPS * CYCLE OF LIFE * RUPTURES * TRANSFORMATION OF THE FAMILIES

El tema de las familias recientemente se presenta como un tópico de interés social, político y académico. Las investigaciones que se han realizado en Latinoamérica y en Costa Rica remiten a un campo de interés donde se

El contenido de este artículo forma parte de una investigación mayor que se realiza como proyecto de tesis para optar al grado de doctorado en El Colegio de México, Centro de Estudios Sociológicos titulada "Amor y señala que los cambios en las macro estructuras - como el mercado laboral y la creciente participación de las mujeres en él- así como los cambios micro sociales - la organización de las familias, la apertura hacia prácticas más

desamor: relaciones de poder en las parejas en tiempos de cambio".

** Escuela de Sociología, Universidad de Costa Rica. npiedraguillen@yahoo.com 
democráticas que cuestionan el modelo patriarcal- refieren a nuevas formas de organización, constitución y composición de las familias.

Al respecto Díaz señala que

La familia convencional, legalmente establecida, constituida por una ama de casa $y$ un proveedor está experimentando un doble retroceso. Por una parte, está descendiendo proporcionalmente en número $y$, por otra parte, se está reduciendo su poder de referente simbólico, casi universal, que hasta hace poco tenía (2004).

Ahora bien, estos procesos no son homogéneos; la complejidad abre las puertas a la diversidad, ya no se habla de la existencia de un solo tipo de familia, sino de los distintos tipos de familias. La heterogeneidad no se restringe a la existencia de la forma de organización, sino también a la heterogeneidad de las actividades que realizan los y las integrantes de las familias, y como estas enfrentan los desafíos de la sociedad actual (que unos llaman posmodernas) (Lyotard, 1992; Jamenson, 1999; Maffesoli, 2000) u otros la nombran como de la modernidad tardía, la segunda modernidad o la modernidad reflexiva (Beck, 2001; Giddens, 1995).

El cambio no solo remite al tipo de conformación de las familias, sino que la noción básica, basada en el precepto religioso y cultural propio de las sociedades modernas occidentales de que las relaciones familiares son para toda la vida también se ha modificado.

Las parejas no son para toda la vida, sino que son familias o parejas permanentemente negociadas y cada vez más desde la igualdad. A pesar del riesgo que entraña el contraste de pareceres, la negociación y la variedad de opciones, las relaciones de pareja aparecen, a los ojos de buena parte de las personas como un ámbito de seguridad personal en el que desarrollar —en compañía- el propio yo, frente al percibido como creciente riesgo social exterior (Díaz, 2004: 11).

Por otra parte, la vida íntima que se genera desde el espacio familiar, cada vez tiene un contenido más público y político, derivado de situaciones particulares que se generan en dicho espacio como son: la violencia intrafamiliar, el reconocimiento de los derechos de niños $y$ niñas, jóvenes $y$ adolescentes como integrantes de estas, o bien de las personas adultas mayores $^{1}$. Así, a las familias ya no se les mira como un grupo homogéneo en su interior, se reconoce la existencia de las particularidades de sus integrantes, sus necesidades, $y$ la interacción de cada cual desde este espacio particular. De ahí que algunas investigaciones se propongan ahora como norte mirar las diferencias, no solo en cuanto a la constitución de las familias - tipologías - sino que también con respecto a las dinámicas internas que se generan en ellas. Si bien este último aspecto es el menos estudiado en este espacio, queda pendiente el tema de las dinámicas internas de las relaciones intrafamiliares, que se abordarán en futuros escritos.

Junto con el análisis de la transformación de la "unidad familiar", el artículo está formado por tres apartados. El primero remite a la delimitación conceptual de la familia; el segundo aspecto desarrollado refiere a los cambios que se han generado al nivel latinoamericano y finalmente, se cierra con un pequeño análisis de la situación costarricense. El objetivo final del documento ha sido el relacionar aspectos conceptuales con el proceso latinoamericano y el costarricense. En este caso observamos como en Costa Rica se desarrolla un cambio más pausado con respecto a la realidad de otros países

1 Por primera vez en Costa Rica el Tribunal de Casación Penal fallo contra un padre de familia y lo condenó con seis meses de cárcel por haber agredido a sus hijas. La agresión ocurrió el 11 de octubre del 2002, el 20 de octubre del 2005 se emitió la sentencia, la cual fue ejecutada recientemente, concediéndosele la ejecución condicional. (Periódico La Nación; sábado 7 octubre del 2006, pág. $6 \mathrm{~A})$. Con este caso se sienta un precedente en el ejercicio de la patria potestad, se cuestiona los límites en el ejercicio de la crianza de las hijas y los hijos, aspecto que nunca antes había sido considerado y penado. Se demuestra que los asuntos privados pueden ser regulados públicamente cuando está en juego la integridad física y emocional de las personas. 
de la región, precisamente es nuestro interés aportar al debate y análisis de la temática.

\section{PROPUESTA CONCEPTUAL DE LAS FAMILIAS}

El concepto de "familia" ha tenido diversas acepciones. Actualmente las familias se están transformando y su modificación se produce por cambios en la esfera socioeconómica, pero también puede considerarse una relación inversa, es decir, observar cómo los cambios que se producen en las familias - por las prácticas e interrelaciones entre las personas que la conforman- posibilitan modificaciones en las estructuras sociales. Es decir, las modificaciones devienen de ambos espacios -individuales $y$ estructurales-. Así como se han transformado las familias, el concepto como tal también ha variado en el tiempo.

En general se identifica la existencia de tres enfoques teóricos como marco de referencia para el estudio de la familia: La teoría funcionalista clásica (donde se ubica Parsons², Linton y en América Latina Germani, así como los estudios de los antropólogos como LéviStrauss $^{3}$ (Salvia, 1995), en donde la familia es

Parsons consideraba que los procesos de la diferenciación estructural que se producen en la sociedad industrial moderna desarrollan un creciente vínculo con las funciones de la familia, dando origen a la familia nuclear. El sistema de parentesco de la sociedad industrial es abierto, multilineal y normado por el sistema conyugal. Este es abierto porque no está basado en unidades de parentesco sumados, como el linaje, grupos o clanes. Es multilineal porque está claramente hecho a partir de reglas de descendencia y es conyugal en tanto hace referencia al matrimonio, o sea la relación entre un esposo y esposa, relación que caracteriza la familia nuclear de procreación. La principal obligación de los esposos unidos es la de proteger a los integrantes de la pareja y a sus hijos e hijas como contraposición con sus familias de origen (Morgan, 1975).

3 Lévi-Strauss, trató de encontrar una explicación que le permitiera identificar rasgos de una estructura universal propia del parentesco humano. Consideraba que la familia surge como mecanismo de defensa para evitar la aniquilación entre grupos rivales. Refuta el evolucionismo biológico al vista como aquella institución que acompaña los procesos civilizatorios ${ }^{4}$. Está el marco conceptual del psicoanálisis de Freud $^{5}$ y la psicología social de Fromm 6 , y, desde una perspectiva

plantear que la familia monogámica existe tanto en sociedades complejas como en las simples “... la familia, constituida por una unión más o menos duradera socialmente aprobada de un hombre, una mujer y sus hijos, es un fenómeno universal que se halla presente en todos y cada uno de los tipos de sociedad" (Lévi-Strauss, 1969). Posteriormente, para delimitar más su análisis acerca de la familia, señaló algunos aspectos que las caracterizan, concepto heredado y retomado ampliamente en los estudios sociológicos, estos son: 1. La familia, cuyo origen principal se da en el matrimonio. 2. Está formada por el marido, la esposa y los hijos nacidos del matrimonio, aunque otros parientes puedan incluirse. 3. Existen entre los integrantes de la familia: a) lazos legales; b) derechos y obligaciones económicas, religiosas y de otro tipo; c) una red precisa de derechos $y$ prohibiciones sexuales, a las que se suman aspectos psicológicos.

4 Lévi-Strauss considera que la familia tiende a ampliarse cuando cumple muchas funciones y a reducirse e incluso desaparecer cuando la familia como institución social pierde funciones. El dispositivo que encontró de orden universal, según su definición es de carácter económico y tiene que ver con la división sexual del trabajo.

$5 \quad$ Freud, por su lado, explica el origen de la familia en función de la desaparición del período de celo y la instalación biológica de la posibilidad de apareamiento sexual entre la pareja. Con un espacio propio el apareamiento se podría dar en cualquier momento del año, los "machos" deciden mantener cerca suyo a la "hembra" que es su objeto de deseo (Freud, 1913). Consideramos que Freud tiene un planteamiento que además de ignorar a las mujeres como sujetas, eleva el aspecto sexual para explicar el origen de la familia a partir de la búsqueda de la satisfacción sexual masculina. Esto debe llamarnos a una reflexión mayor, pues se asocia sexualidad y ejercicio de la misma con relaciones de poder. Esta explicación contrasta con la realizada por los antropólogos y sociólogos, ya que enfatiza en un aspecto psicosexual. Se puede decir que dicha explicación es reduccionista $y$ androcéntrica pero que encara fríamente un aspecto de la relación de poder que subyace en la relación de pareja.

$6 \quad$ Fromm considera que las relaciones de mercado inciden en las relaciones familiares, existiendo así un fuerte vínculo entre desarrollo económico y familia (Salvia, 1995). 
más amplia, se ubican los trabajos de Marx, Engels ${ }^{7}$, Weber y Horkeimer que analizan cómo los procesos económicos, sociales y culturales del capitalismo han incidido en la familia como instancia o institución que responde a los requerimientos productivos de cada período o modo de producción.

No obstante la existencia de estos tres enfoques, se puede decir que las conceptualizaciones de la familia como institución, así como aquellos aspectos que explican el surgimiento de la misma están vinculados a dos aspectos medulares: el biológico centrado en la sexualidad y la procreación; $y$ un segundo enfoque que mira a la familia como una institución social en la que se llevan a cabo las funciones sexuales $y$ procreativas (este segundo enfoque de acuerdo con Jelin (1998) y a Salvia (1995) incluiría las corrientes funcionalistas como las economistas); elementos que están presentes en la conceptualización que se hace sobre la familia "nuclear" que ha constituido el ideal de familia en la sociedad contemporánea ${ }^{8}$.

$7 \quad$ Federico Engels afirmó que las sociedades primitivas o simples se reducen al parentesco, mientras que las sociedades complejas, donde se ha constituido el Estado, el parentesco cede su importancia al orden de la propiedad, originándose una nueva forma de organización social, la familia. "Utilizando la lógica de las relaciones de clase para entender los vínculos entre géneros, supuso que estos nuevos ricos, una vez comprendido su rol en la reproducción humana, habrían utilizado su poder para instaurar la monogamia y la filiación patrilineal, a fin de asegurarse la legitimidad de la descendencia y poder transmitir los bienes que no alcanzaran a consumir a quienes pudieran considerar extensiones de su ser, o sea sus hijos biológicos" (Burin y Meler, 1998: 37).

Sin embargo, queda por responderse a la pregunta de ¿Cómo surge la familia nuclear? Al respecto Sáez Buenaventura (1979) señala que en el siglo XVIII la revolución industrial trajo consigo enormes cambios como la urbanización, una nueva ética, en la cual la razón sustituyó los principios religiosos. "Las figuras religiosas de autoridad se sustituyen por autoridades seculares (la figura del soberano absoluto) que rigen a los ciudadanos. La antigua casa medieval, que era unidad de producción y de consumo, va cambiando hasta transformarse en la familia nuclear" (Burin y Meler, 1998: 75). En el período pre industrial el padre era la figura de auto-
De acuerdo con Foucault, hasta el siglo XVII existía cierta franqueza $y$ desinhibición en aspectos relativos a la sexualidad. Los cuerpos se exhibían y pavoneaban ${ }^{9}$ contrastando con el período industrial en donde la única sexualidad reconocida es la "utilitaria y fecunda", la reproductora (Foucault, 1999). La sexualidad en dicho período estaba delimitada al ámbito de la familia, a partir de la constitución de la pareja conyugal como expresión de un vínculo fundado en la religión católica. La sexualidad fue delimitada así al poder-saber de la época, o sea el discurso elitista y moralista de la sociedad burguesa:

La idea del sexo reprimido no es pues sólo una cuestión de teoría. La afirmación de una sexualidad que nunca habría sido sometida con tanto rigor como en la

ridad. Su dominio se extendía más allá de su familia consanguínea abarcando a los aprendices y los siervos que ayudaban al sostén familiar. Los bienes acumulados se transmitían a través de la herencia y las mujeres a pesar de que dependían del padre-patrón, participaban en la producción de bienes y en la reproducción. La separación entre trabajo doméstico y productivo no correspondía o no estaba del todo delimitada como ocurre con la consolidación de la familia nuclear. La familia en el período industrial se tornó en una institución relacional y personal, se constituye así como el espacio íntimo, privado de la sociedad. El espacio de interacción familiar se redujo, así como la delimitación de una serie de funciones que con el tiempo se tornaron como "naturales", propias de la vida en familia y sobre todo de las tareas de las mujeres, tales como la realización de las tareas domésticas, consumo, crianza de los niños, lo privado e íntimo de los vínculos afectivos (Burin y Meler, 1998). La atención de los niños y niñas se convirtió en una de las labores centrales de las mujeres, razón por la cual la misma se aísla del entorno social para cumplir con su labor. Se crea un ideal de mujer, esta vez relacionado con su función materna. La sociedad industrial no sólo cambia las relaciones de trabajo y económicas entre los géneros al interior de la familia, sino que confisca, constriñe, encierra y absorbe la sexualidad de hombres y mujeres, delimitándola a la función central reproductora.

$9 \quad$ Esta experiencia era propia de los hombres de las clases altas, por ejemplo de la Grecia clásica, quienes podían no sólo tener relaciones homosexuales sino mantener una estrecha relación emocional con algún amigo exclusivo (Foucault, 1999). 
edad de la hipócrita burguesía, atareada $y$ contable, va aparejada al énfasis de un discurso destinado a decir la verdad sobre el sexo, a modificar su economía en lo real, a subvertir la ley que lo rige, a cambiar su porvenir (Foucault, 1999: 15).

La sexualidad pasa a ser regulada por la familia, institución que además es la depositaria de infinitas políticas de población, finalmente creadas para controlar el cuerpo de las personas. A través de la familia no sólo se controla la sexualidad de las mujeres, sino la de los niños, niñas, jóvenes y adolescentes en general. El Estado necesita regular la sexualidad al considerar que existen problemas económi$\cos y$ políticos relativos a las "necesidades de población". Se pasa así al análisis sistemático de la natalidad, morbilidad, duración de la vida, fecundidad, estado de salud, frecuencia de enfermedades, formas de alimentación y de vivienda. Según Foucault, dicho proceso de control poblacional está relacionado con el "biopoder" propio de la sociedad contemporánea disciplinaria ${ }^{10}$.

Entonces, para los alcances de este artículo la familia será definida como: una institución social central en la organización genérica, en la medida en que existen al interior poderes, jerarquías $y$ valores producto de las diferencias de género. Dicha institución a su vez cumple con funciones económicas, socializadoras e ideológicas. Cumple así un papel importante en la constitución de la identidad de género, subjetiva y simbólica, de sus integrantes.

La definición propuesta recoge tanto los aspectos estructurales como los psicosociales presentes en algunas de las explicaciones planteadas al inicio del apartado. No se pretende formular explicaciones universalistas tipo Parsons

10 El planteamiento de Foucault coincide con el que realizan Burin y Meler al considerar que "en el corazón de este problema económico y político, los estados deben desarrollar estrategias de control social para la sexualidad: hay que analizar la tasa de natalidad, la edad de matrimonio, los nacimientos legítimos e ilegítimos, la precocidad $y$ la frecuencia de las relaciones sexuales, el efecto del celibato, la incidencia de las prácticas anticonceptivas, etcétera" (Burin y Meler: 1998, 88). o Lévi-Strauss con respecto a las familias; precisamente, se adopta el análisis foucaultiano que relaciona aspectos como estructura familiar, sexualidad $y$ relaciones de poder (biopoder). Con el desarrollo del capitalismo deviene la necesidad de control sobre los cuerpos y en particular sobre la sexualidad de las personas, para Foucault la familia como institución es el espacio ideal para ejercer dicho control. Por tanto, en la actualidad cuando nos referimos a los cambios que se están dando en las familias, hablamos de una transformación de carácter estructural, pues el ejercicio de prácticas tradicionales, son las que entran en cuestionamiento y están teniendo una incidencia en el proceso societal.

Algunos autores $y$ autoras proponen que en el análisis de la familia se debe cuestionar la visión y división esquemática de lo micro $y$ macro social, es decir la relación "familiasociedad" por un lado y la "familia-individuos" por el otro. Para descentrar el enfoque esquemático han propuesto la articulación de estas dimensiones a través de la interrelación de tres ejes: el proceso histórico, las trayectorias de vida y el curso de vida de los y las integrantes (Yanagisako, 1979; Hareven, 1988, 1982 y 1990; Jelin, 1994, entre otras y otros autores).

El considerar los tres ejes antes señalados $y$ sus diferentes temporalidades posibilita un enfoque alternativo integrador de las relaciones domésticas y familiares como prácticas estructuradas y a la vez estructurantes (Giddens, 1981; Bourdieu, 1979; Oliveira, 1998b; Salles, 1988a; Salles, 1993). Las prácticas y los comportamientos objetivos, permite observar a su vez valores, normas y signos (Habermas en Salles, 1991 y 1993).

Es necesario articular el ámbito de lo social — familias - con el individual. De esta forma

[la] unidad doméstica puede ser definida como un ámbito social, cultural e históricamente situado de interacción $y$ de organización de procesos de reproducción económica, cotidiana y generacional, existe un espacio de interrelaciones materiales, simbólicas y afectivas en donde tiene lugar la formación y socialización primaria de los individuos y el 
reforzamiento de las actividades grupales. Un ámbito en el que también se crean y recrean de manera particular relaciones sociales de intercambio $y$ de poder, de autoridad, solidaridad y conflicto -Yanagisako, 1979; Jelin, 1994; Cortés-Cuellar, 1990; Salles, 1991; GarcíaOliveira, 1994- (Salvia, 1995: 10).

Así, las familias son instancias de mediación entre el individuo y la sociedad, una especie de lazo entre lo macro y lo micro social, de ahí que entender lo que sucede en este espacio articulador de lo personal y lo social es determinante para comprender los cambios que se están dando al nivel de las subjetividades y de las sociedades.

\section{LAS FAMILIAS Y SUS TRANSFORMACIONES RECIENTES}

En este segundo apartado se analiza el proceso de desarrollo y los cambios que se han suscitado en las familias durante las últimas décadas. En tanto institución social la familia juega un papel importante; su estructura se diversifica cada vez más, y las funciones que desempeña se han ido transformando significativamente a lo largo del tiempo. En décadas anteriores, se consideraba a la familia nuclear como un "pilar" central y fundamental en la sociedad. Sin embargo, al estudiar el tema de la "familia" en América Latina, se observa que "la misma" no siempre se estructuró en torno al modelo de la familia nuclear.

Según la CEPAL, en los países desarrollados los cambios se han caracterizado por ocurrir durante un largo periodo, mientras que en América Latina y el Caribe se han producido en un tiempo más corto y son más recientes. Las principales modificaciones han coincidido con el desarrollo de procesos de modernización institucional, industrialización y urbanización (CEPAL, 1994 y 2004). Los estudios arrojan interesantes datos sobre las modificaciones en curso, que se sustentan en aspectos teóricos, sociológicos y demográficos; sin profundizar en los aspectos psicosociales que se producen en las familias a partir de los cambios que se dan en la práctica.
Algunas de la transformaciones más significativas que se han dado en la estructura familiar son: la reducción del tamaño de las familias, creciente inestabilidad en los arreglos familiares (más divorcios y separaciones), incremento en las relaciones premaritales, aumento en el número de hogares en los que ambos cónyuges trabajan; incremento de los hogares uniparentales, incremento de familias integradas por convivientes que no formalizan legalmente su unión, integraciones multifamiliares, así como nuevos arreglos para la crianza de los hijos e hijas (CEPAL, 1994; Arriagada, 1997). Uno de los factores detonantes de este proceso de cambio ha sido la creciente incorporación de las mujeres en el mundo del trabajo. Este fenómeno ha generado tensiones en los hogares, pues la generación de ingresos es compartida; $y$, en situaciones extremas, donde la mujer desplaza al varón como fuente principal de ingresos de la familia, la violencia contra la mujer tiende a agudizarse (De Oliveira, 1999).

La integración de las mujeres en el ámbito laboral incide en las transformaciones de la vida familiar, lo cual se asocia con su mayor independencia económica, ampliación de sus derechos sociales $y$ emergencia de nuevos valores y cambios en los roles de género. Un tema que se ha replanteado en las relaciones intrafamiliares es el de la toma de decisiones; tradicionalmente, los varones, en tanto jefes de familia, tenían un mayor control sobre la administración de los recursos económicos y el control de la vida de sus integrantes, mientras que, las decisiones de crianza, educación, y acompañamiento emocional de las y los hijos han sido más del orden doméstico y por ende de las madres.

Otros factores que han incidido en el cambio son: los demográficos, tales como la reducción de las tasas de fecundidad; aumento en la esperanza de vida y la concentración del ciclo reproductivo en las primeras etapas de la unión conyugal. Los factores tecnológicos, referidos a la disposición de una gran cantidad de electrodomésticos que facilitan el desarrollo de las tareas domésticas. Los factores sociopolíticos relacionados con la expansión de los servicios sociales de cuido y educación de niños y niñas. Factores sexuales como cambios en ciertas prácticas sexuales, se constata 
una disminución en las restricciones sexuales, el inicio más temprano de las mismas, una sexualidad con mayor acceso al uso de métodos anticonceptivos (Jelin, 1994). Aunque estudios realizados en diferentes ciudades de México señalan que el dominio masculino sobre las mujeres se sigue ejerciendo, ya que los hombres casi siempre deciden y toman la iniciativa en la relación sexual (Oliveira, 1998a).

Actualmente, se clasifican las familias según su estructura para mostrar la heterogeneidad, se suelen identificar cinco tipos de familias: la unipersonal, la nuclear, las extensas, las compuestas, $y$ las monoparentales ${ }^{11}$. Según Arriagada la mayoría de las familias en América Latina son nucleares (compuesta por uno o ambos padres, con o sin hijos) por ejemplo, en 1994 en Paraguay el 55\% de la familias eran nucleares y en México, Brasil y Bolivia constituían aproximadamente el $70 \%$ y en Costa Rica el $68,2 \%$. Sin embargo, no se debe menospreciar las modificaciones que paulatinamente se muestran con respecto a los otros tipos de familias, como las extensas (madre-padre e hijos con otros parientes) que en las zonas urbanas representan un 13\% en Argentina, un $31 \%$ en Venezuela y en Costa Rica un 19,3\%. Las familias compuestas (familias nucleares 0 extensas que incluyen a personas no parientes) muestran una tendencia de menor peso en la mayoría de los países latinoamericanos, excepto en Paraguay que tiene un $8,8 \%$ en 1994. Los

11 Por hogares unipersonales entendemos aquellos que están constituidos por una sola persona. El hogar nuclear corresponde al ideal prototípico que está constituido por un jefe de familia y su cónyuge con o sin hijos e hijas, o bien sólo el jefe con sus hijos (esta última opción del modelo nuclear corresponde principalmente a los hogares jefeados por mujeres). El hogar extenso está formado por el jefe y su cónyuge con o sin hijos e hijas, o sólo el o la jefe con los hijos e hijas y otros parientes. Los hogares compuestos están integrados igual que los nucleares o extendidos, más otras personas que no son parientes consanguíneos (excluidos los y las trabajadoras domésticas). Por último tenemos a los hogares monoparentales que corresponde a aquellos que están constituidos por un jefe o jefa que vive con sus hijos e hijas $\mathrm{u}$ otros familiares 0 con amigos $y$ amigas (Arriagada, 1997). hogares sin núcleo, constituido por personas sin relación de filiación alcanzan entre un 4\% $y$ un $6 \%$ en los 12 países estudiados y los unipersonales van de un $3 \%$ a un $15 \%{ }^{12}$. En Costa Rica representan un 3,7\% y en México un 4,3\% (Arriagada, 1997; 2004).

Dentro de las familias nucleares son mayores los hogares compuestos por una jefatura masculina, los porcentajes van de un $48 \%$ en Paraguay y Venezuela a un $63 \%$ en Bolivia y México en 1994. En Costa Rica los hogares nucleares con jefatura masculina son el 57\% para el mismo año. La jefatura femenina representa un $10 \%$ en Costa Rica hasta un 7,2\% en Argentina.

Se observa que las familias extensas o compuestas tienen una mayor incidencia que las familias biparentales (con jefe y cónyuge). Las familias monoparentales en general, sobre todo los hogares con jefatura femenina han aumentado con el tiempo, alcanzando un $14 \%$ en Bolivia y México; un 26\% en Uruguay. En Costa Rica las familias biparentales representan un $22 \%$ en 1994.

Los fenómenos que se asocian con el aumento de los hogares monoparentales con jefatura femenina son: aumento en separaciones $y$ divorcios, incremento de la fecundidad adolescente (que no implica el matrimonio), migración laboral de esposos y viudez.

En los hogares unipersonales entre 1986 y 1994 hubo un aumento considerable en la magnitud. Dicho aumento obedece principalmente a tendencias de envejecimiento de la población. Esta característica se observa con mayor proporción en Argentina y Uruguay, ya que son países con una transición demográfica avanzada. A su vez, este fenómeno se observa más en el caso de las mujeres, lo que se explica por la esperanza de vida, que es mayor a la de los hombres. Algunos porcentajes son: Costa Rica 4,4\%, México 5\% y Argentina un 11\%.

Otro aspecto de igual importancia a considerar, alude a las diferencias que se presentan

12

A continuación señalamos cuáles son los países que formaron parte del estudio realizado por Irma Arriagada; Argentina, Bolivia, Brazil, Chile, Colombia, Costa Rica, Honduras, México, Panamá, Paraguay, Uruguay y Venezuela. 
en los distintos tipos de familia dependiendo de la etapa del ciclo de vida ${ }^{13}$ en la que cada cual se encuentre. En casi todos los países - para los cuales se encuentra con información comparable - entre 1986 y 1994 hay importantes cambios en la magnitud de las familias en las distintas etapas del ciclo familiar, sobre todo en aquellas unidades en las que se cuenta con hijos menores de 12 años. Las unidades familiares "se redujeron en algo menos de la mitad y aumentaron en las otras categorías. La fuerte caída en sólo 8 años de los hogares con hijos pequeños, refleja el descenso de la tasa de natalidad de los años setenta" (Arriagada, 1997: 15). Hacia 1994 muchas de las familias se encontraban en la etapa III —-donde el hijo mayor tiene más de 19 años - representando el 30\% en Bolivia y Brasil, un $44 \%$ en Chile y Venezuela y un 27\% en Costa Rica.

En general se puede plantear que las transformaciones han incidido en el modelo ideal de familia - el nuclear-. Dicho modelo ha cambiado en la práctica, adecuándose a los procesos sociales, económicos y culturales de las sociedades contemporáneas. Los cambios que aluden a la composición de las familias identifican cinco tipos como ya se ha señalado los hogares unipersonales, nucleares, extensos, compuestos y sin núcleo.

El panorama se vuelve más complejo $y$ heterogéneo cuando se considera ya no sólo los tipos de unidades familiares que existen $y$ que rompen con el modelo tradicional de la familia nuclear, al considerar otras expresiones como los arreglos familiares no residenciales. Por lo general, los estudios realizados privilegian las familias con corresidencia sin tomar en cuenta aquellas que no viven bajo el mismo

En general se habla de cinco etapas en el ciclo de vida de las familias: Etapa inicial, cuando se forma la pareja y no tienen hijos. I Etapa, que corresponde al nacimiento del primer hijo o hija. II Etapa, cuando el hijo o la hija mayor del jefe o jefa de familia tiene entre 13 y 18 años. III Etapa, cuando el hijo o la hija mayor del jefe o jefa de la familia tiene más de 19 años y la IV Etapa, reconocida como el nido vacío — pareja adulta sin hijos, donde la cónyuge es mayor de 35 años y no tienen hijos ni hijas que vivan con la pareja (Arriagada, 1997). "techo"; estas últimas "familias encabezadas por mujeres con pareja ausente temporalmente" (Oliveira, 1998a). Se trata de unidades familiares en donde el compañero (o la madre de familia) labora en otra región (caso de mujeres $\mathrm{u}$ hombres que migran a los centros urbanos nacionales en busca de mejores oportunidades laborales), o bien aquellos que migran a otros países. Por ejemplo, en el caso de personas centroamericanas es muy común que migren a Estados Unidos, México, o incluso Costa Rica.

En el Caribe tenemos otro tipo de arreglos familiares no corresidentes llamados "uniones de visita".

Se trata de familias conformadas por la pareja, con hijos, que viven en casas aparte pero comparten, además del vínculo sexual, múltiples formas de convivencia: recreación, socialización de los hijos, procesos de toma de decisiones. La pareja se constituye a edades tempranas a partir de relaciones conyugales que no están sancionadas legalmente, sino que son normadas por pautas y prácticas sociales establecidas, $y$ por lo general tiende a legalizarse a lo largo de la vida de las mujeres (Oliveira, 1998a: 40).

A su vez, siguiendo la propuesta analítica de Oliveira, debemos distinguir entre las familias con jefatura femenina en las cuales las jefas no tienen cónyuge, de las familias con jefatura femenina en donde las jefas conviven con el cónyuge. Las condiciones de vida suelen ser diferentes para cada caso. Al estudiarse a las jefas sin cónyuge se reportaron formas de convivencia familiar menos violentas que aquellas en donde la jefa de la familia convive con su cónyuge. Al parecer los varones sienten que han fracasado en su papel de proveedor, hacen uso de la violencia física y psicológica para reafirmar su autoridad que consideran perdida o desplazada (Oliveira, 1998a).

Para concluir este apartado podemos decir en términos generales que las condiciones económicas, sociales y culturales se están transformando, que dichos aspectos repercuten en la constitución de las familias, así como en las funciones que estas deben desempeñar y que dichas 
modificaciones han afectado positivamente $y$ negativamente a las familias. Positivamente, porque hay mayores espacios de acción y libertad sobre todo en el caso de las mujeres, que al tener acceso a una serie de recursos han alterado su condición de subordinación empezando a crear identidades de género más autónomas. Por otra parte, decimos que hay efectos negativos en la medida en que la crisis y reestructuración económica han impactado a muchos hogares en donde la incorporación de las mujeres al mercado de trabajo ha sido una necesidad más que un aspecto de realización personal.

En los hogares monoparentales disminuyeron las familias con jefatura femenina con jefas solteras de un 29,4\% a 26,9\% entre 1984 $y$ el 2000. Mientras que las familias de jefas $y$ divorciadas $y$ separadas aumentaron de un $34,4 \%$ a un $46,0 \%$ (1984 y 2000 , respectivamente). Otro aumento significativo, que llama la atención es el de las familias con jefes divorciados y separados que va de un 22,8\% (1984) a un 41,2\% (2000), así como el de los jefes solteros que aunque más leve, no deja de ser importante de señalarse, pues pasó de un 9,3\% en 1984 a un $11,1 \%$ en el 2000. En la gráfica que se presenta a continuación se observa claramente las tendencias generales, con respecto al estado conyugal de los jefes $y$ jefas de familia.

La pobreza ha obligado a que niñas $y$ niños, adolescentes y jóvenes de ambos sexos $y$ mujeres adultas tengan que incorporarse al mercado laboral. Los trabajos a los que acceden se caracterizan por su precariedad, inestabilidad, bajos salarios, etcétera. Por tanto, podemos afirmar que la función socializadora de las familias no está orientada siempre a la promoción de la equidad social. Por el contrario, la familia suele ser un espacio de producción/reproducción de desigualdades sociales en la medida en que trasmite privilegios, de hecho $y$ derecho, restringe el igual acceso de oportunidades y norma la desigual distribución de los recursos entre sus integrantes (CEPAL, 1994).

\section{GRÁFICO 1}

TOTAL DE FAMILIAS SEGÚN ESTADO CONYUGAL DE JEFATURA

1984,2000

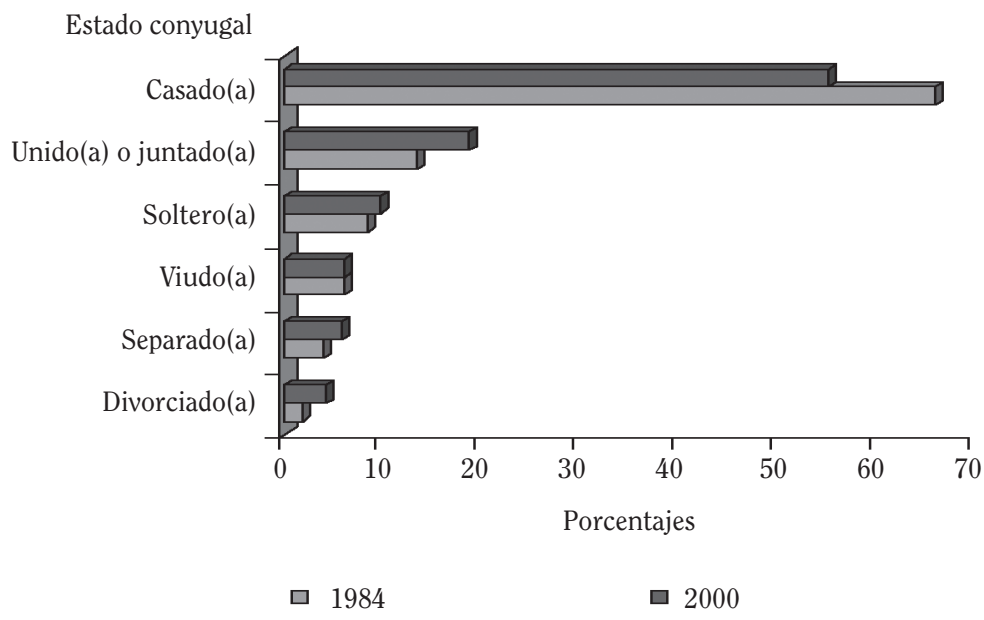

Fuente: UNICEF IV Estado de los derechos de la niñez y la adolescencia en Costa Rica. Universidad de Costa Rica. San José, Costa Rica. 2004. 


\section{COSTA RICA Y LOS PROCESOS DE CAMBIO EN LAS FAMILIAS}

Desde la década del noventa en Costa Rica se da inicio a un proceso de análisis sobre el tema de las familias. De los estudios realizados entre 1990 y 1995 destacan el análisis exploratorio y descriptivo, "domina la investigación aplicada y existe una ausencia de estudios que emplean modelos explicativos" (Vega, 2000: 14). Mayoritariamente se trataron temas sobre violencia y salud, le secundan temas sobre el trabajo infantil, educación, terapia familiar y adopciones. En años más recientes se han realizado investigaciones que tratan el tema de la familia tanto en el ámbito histórico, de la psicología social y el sociológico, enriqueciendo los estudios de los noventa como son los trabajos de Vega: 1993, 1996, 2000, 2003a y 2003b; Vega y Cordero: 2001; Guzmán: 1994 y 2001; Batres y Claramut: 1993; Claramut: 1997; Rodríguez: 1997, 2000 y 2001; y Reuben: 2000.

Por lo general los estudios señalan los cambios que vive el país en la estructura familiar como; aumento de jefatura femenina, de familias uniparentales, aumento en los divor$\operatorname{cios}^{14}$. Este apartado tiene como fin mostrar las

14 Otros estudios sobre las mujeres han evidenciado la violencia intrafamiliar, y en particular, sus efectos sobre las mujeres como población que se encuentra en riesgo de ser abusada y agredida por su condición de género; de esta forma, la casa y la familia son espacios amenazantes y poco seguros para este grupo de mujeres (véase Batres y Claramunt, 1993; Claramunt, 1997; Guzmán, 1994; Quirós y Barrantes, 1991; Rodríguez, 198). Estos estudios logran romper con la idea de la mujer víctima y reivindican la capacidad de resistencia de las mujeres, señalando la relación de poder asimétrica a lo interno de las familias como factor que influye en la experiencia de violencia (Guzmán, 2001). Con respeto a la jefatura femenina y la familia, se encuentra en la bibliografía especializada dos trabajos que se realizaron recintemente. En ellos se cuestiona la relación que se ha establecido entre jefatura femenina y pobreza, en la medida en que dicha percepción alimenta estereotipos de género y "victimiza" a las mujeres (Cordero, 1998). Por otra parte, se caracteriza a las jefas de familia, dferenciado las jefas económicas de las no económicas. De los datos que presenta el autor se desprende que son las jefas no económicas las que se encuentran en una posición más vulnerable. Este transformaciones en las familias costarricenses de forma más detallada. No sin antes señalar, que los mismos cambios según se ha destacado en distintos estudios, plantean debates $y$ aspectos que hay que profundizar en el estudio de las familias $y$ las parejas.

Por ejemplo, a veces se señala que la estructura, es decir la composición de las familias sigue teniendo un corte tradicional, de familias nucleares, mientras que los otros tipos de familias no tienen aún un peso relevante en la organización, además las relaciones de parentesco, el estatus y la autoridad de la mujer en el hogar, no muestran mayores cambios a lo largo de los últimos años. Al respecto Vega plantea que se mantiene la predominancia de familias patriarcales con un padre de cabeza de familia $y$ figura de autoridad, los estereotipos de hombre fuerte $y$ proveedor y mujer doméstica siguen imperando. Si bien hay un proceso de cambio en el papel de la mujer en la sociedad y en la familia, todavía es clara la influencia de ideas tradicionales en torno al lugar que debe ocupar como esposa y como madre, a la vez que se plantean contradicciones entre los estereotipos familiares $y$ los hechos de la realidad concreta (Vega, 1993, 2001).

La misma autora señala, que la incorporación de las mujeres al mercado laboral, "ofrece a estas la oportunidad de ampliar su círculo de interacciones sociales $y$ de enriquecer su autoestima, su experiencia vital y su visión del mundo" (Vega, 2001: 207). Considera a su vez, que los cambios pueden incidir en la dinámica familiar $y$ en el proceso de socialización de sus hijos e hijas. Pero también; genera inestabilidad a la familia como institución. Se observa así, como el proceso es complejo, contiene contradicciones y el mismo no es lineal.

Particularmente considero que el análisis de las prácticas concretas entre hombres y mujeres en la pareja es fundamental para estudiar la dinámica de las parejas, sus relaciones de poder, así como la familia en general. Y que, a pesar de la predominancia de las familias nucleares existe

grupo se caracteriza por tener un nivel educativo menor, realizar actividades en el sector servicios y de tipo informal y casi no participan en espacios de organización social (Cordero. 2001). 
en la práctica una destradicionalización de las relaciones de las parejas o de las familias (Beck, 2001). Hay un peso importante en la afirmación de este tipo de relaciones familiares o forma de vínculo, —como ejemplo tenemos a las parejas de gays y lésbicas que luchan para que sus uniones se reconozcan legalmente, también están las relaciones familiares múltiples producto de segundas o terceras uniones - pero la dinámica a su interior se empieza a desarrollar bajo nuevas bases. Mantener una unión ya no sólo se fundamenta en la idea del sentido común, la racionalidad y la conveniencia sino que también en la idea del "amor romántico" (Díaz, 2004) así que la realización afectiva, adquiere un peso importante en las relaciones de pareja y en las familias, fenómeno que se observa con mayor claridad en la zonas urbanas que en la rurales.

Lo que deseo destacar del caso costarricense es que si bien las familias nucleares siguen siendo mayoritarias, tal $y$ como lo muestran las estadísticas y que los cambios a diferencia de otros países latinoamericanos son más paulatinos; las relaciones familiares, $y$ en específico las relaciones de pareja se están transformando. A pesar de que el "esquema" o conformación sigue siendo el "mismo", las relaciones, las interacciones y las costumbres pueden variar en su interior, promoviendo así modificaciones cotidianas que luego repercutirán en la estructura social, existe una destradicionalidad de las relaciones de pareja y familiares.

La permanencia de la familia nuclear como forma prototípica de la organización familiar no implica la existencia de un poder masculino permanente e incambiable en el tiempo, para estudiar esta dinámica es necesario profundizar en las percepciones, prácticas y discursos de las y los sujetos en cuestión (aspecto que se profundizará en otro espacio de reflexión). Notamos una tendencia a que las necesidades y los intereses de las mujeres en las familias sean considerados en la dinámica cotidiana; en mayor o menor medida en cada hogar, este "pequeño" hecho tiene un carácter rupturista y consecuencias en las prácticas de las parejas y sus familias de relevancia.

A su vez hay que considerar que las dinámicas de las familias en una sociedad refleja los distintos modelos de desarrollo y los valores que predominan en un período históricosocial. En Costa Rica, la historia social permite entrever una red de significaciones sobre las mujeres y las familias, sustentada en la supremacía patriarcal (Vega, 2000). Con respecto a la familia, en Costa Rica según detallan estudios historiográficos, desde antes de la llegada del café, existieron diversos tipos de familias, en donde imperaba la nuclear. La información disponible para el caso costarricense no indica la existencia de familias extendidas o numerosas como forma de organización significativa (Gudmundson, 1986; Vega, 2000, 1997). Las familias nucleares - padre, madre e hijos o hijas solteras- precedieron como patrón familiar al capitalismo agrario, sin embargo, el impacto de la cultura del café, si impulsó la formación de estos hogares nucleares (Gudmundson, 1986).

Señala Rodríguez que, "durante el siglo XIX el matrimonio tendió a generalizarse $y$, ligado a ellos, los nacimientos ilegítimos comenzaron a descender" (Rodríguez, 2000: 19); las tasas fluctuaron 10 y $20 \%$ en la primera mitad del siglo XIX. Esta experiencia se acerca más a la de Europa Occidental que a la del resto de Latinoamérica. Dentro de los factores que se asocian con la generalización del matrimonio se destaca principalmente la expansión de la agricultura del café; los matrimonios en la población mestiza; el matrimonio entre los artesanos y propietarios agrícolas medios y acomodados del Valle Central que se casaban para consolidar $y$ legitimar la riqueza y la cobertura geográfica de la iglesia católica y del Estado, que se acentuó durante el siglo XIX (Rodríguez, 2000).

También la investigación histórica ha demostrado que el matrimonio no fue la única base de constitución de las familias, por eso es necesario considerar que la diversidad ha existido en nuestro país y, en las últimas tres décadas. 
Así como, el proceso de desarrollo del café tuvo su impacto en la estructura familiar $y$, posteriormente el desarrollo de la industria $y$ la urbanización generada en la década de 1950, ahora, situaciones más recientes como la crisis económica de los años 80s, la reestructuración de los años 90s y la globalización, están teniendo su impacto particular en la constitución de las familias, respondiendo a necesidades $e$ intereses particulares de las personas y de los cambios estructurales.

Una de las variaciones que se han señalado en diversos estudios refiere a que la estructura familiar reciente muestra modificaciones, siendo una de las más relevantes la disminución del peso relativo de las familias nucleares con hijos e hijas (Vega, 1997, 2000; Cordero, 1998; Reuben, 2000 y Programa Estado de la Nación, 2004). No implica tal tendencia, que persistan los hogares nucleares (con y sin hijos e hijas). Para el 2002 el porcentaje de hogares nucleares fue del $70 \%$, en segundo lugar aparecen los hogares extensos con un $20 \%$ y el restante $10 \%$ se distribuye entre los hogares compuestos y los unipersonales, los que muestran un aumento importante de un 4,9\% en 1987 a un $7 \%$ en el 2002. También hay un aumento en el número de hogares monoparentales, lo que se observa en el cuadro 1.

CUADRO 1

COSTA RICA: DISTRIBUCIÓN RELATIVA DE HOGARES POR AÑOS, SEGÚN TIPO 1987, 1994, 2002

\begin{tabular}{lrrr}
\hline TIPO DE HOGAR & 1987 & 1994 & 2002 \\
\hline Nuclear sin hijos/as & 6,4 & 8,0 & 8,6 \\
Nuclear con hijos/as & 56,1 & 51,4 & 49,7 \\
Nuclear monoparental & 8,7 & 9,6 & 11,8 \\
Extenso sin hijos/as & 1,6 & 1,8 & 1,4 \\
Extenso con hijos/as & 10,7 & 10,9 & 9,0 \\
Extenso monoparental & 5,2 & 6,3 & 6,8 \\
Extenso sin núcleo & 2,8 & 3,1 & 2,9 \\
Compuesto nuclear & 2,0 & 1,8 & 1,3 \\
Compuesto extenso & 0,9 & 0,7 & 0,6 \\
Compuesto sin núcleo & 0,1 & 0,2 & 0,2 \\
Unipersonal & 4,9 & 5,7 & 7,0 \\
No familiares & 0,5 & 0,5 & 0,5 \\
Total & 100,0 & 100,0 & 100,0 \\
\hline
\end{tabular}

Fuente: Programa Estado de la Nación. Décimo Informe Estado de la Nación en Desarrollo Humano Sostenible. San José, Costa Rica. 2004.

Otro aspecto destacable es el incremento de los hogares jefeados por mujeres, en especial de los hogares con hijos e hijas y sin compañero. "Aunque los hogares con hijos tienen a un hombre como jefe de hogar en poco menos de dos terceras partes $(64,1 \%$ en 2002$)$, sobresalen los hogares con mujeres jefas en los tipos monoparentales nucleares y extensos $(43,1 \%$ y $24,5 \%$ respectivamente) (Programa Estado de la Nación, 2004).

Por otra parte se observan cambios de las jefas $y$ los jefes de hogar con respecto a su estado conyugal. Se tiene que los hogares con jefatura en condición de divorcio se duplicaron entre 1984 $y$ el 2000 , de $2,0 \%$ a $4,2 \%$ respectivamente. Por su parte, las familias con jefatura en condición de casada descendieron de $61,9 \%$ en 1984 a 55,3\% en el 2000 y las familias con jefes y jefas en uniones de hecho, aumentaron de $13,8 \%$ a $18,8 \%$ (entre 1984 al 2000 respectivamente). Mientras que, las familias con jefatura en condición de soltería aumentaron de 7,5\% en 1984 a 9,9\% en el 2000 respectivamente (ver cuadro 2 y 3 , se presentan cuadros para cada año 1984 y 2000). 


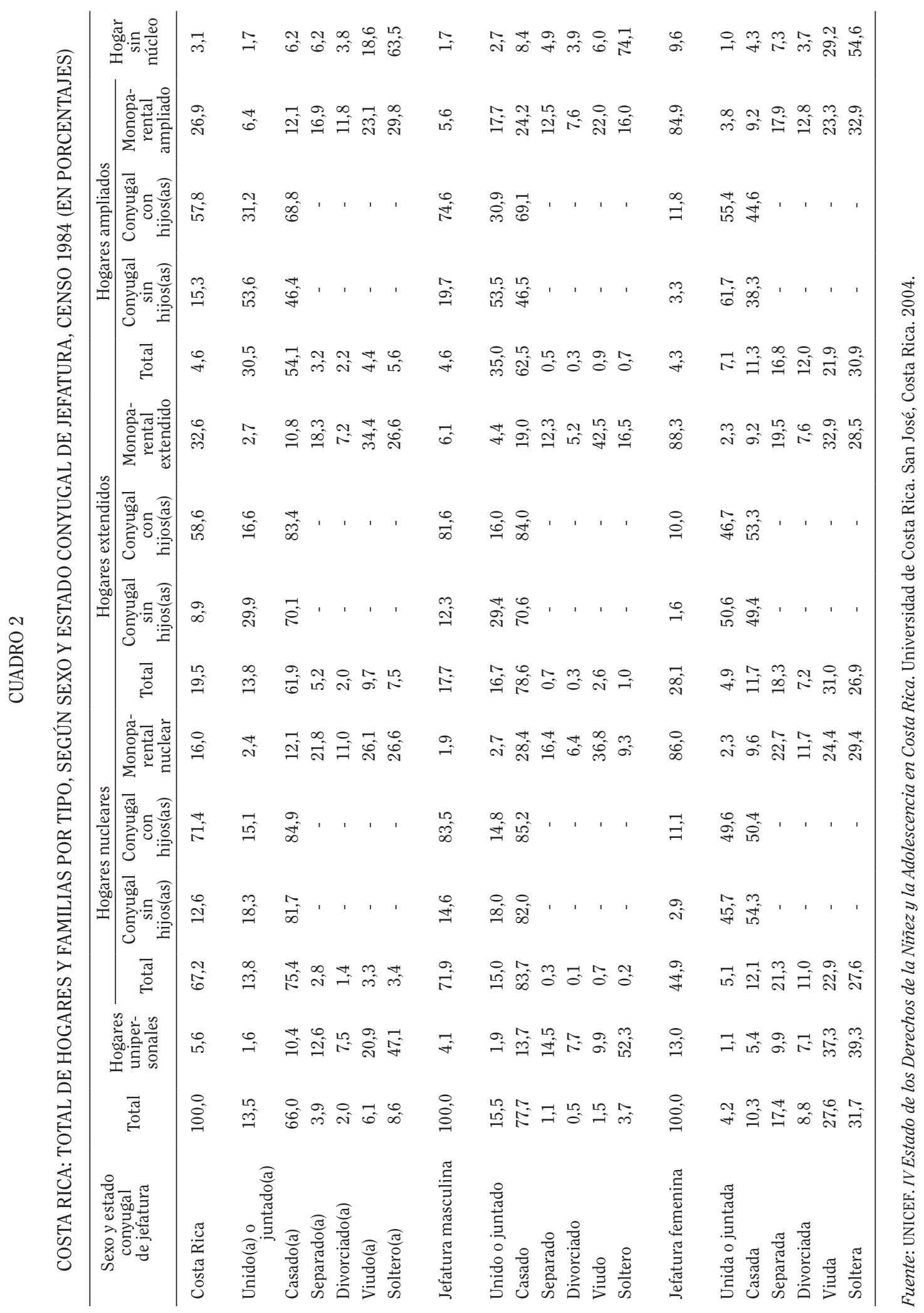




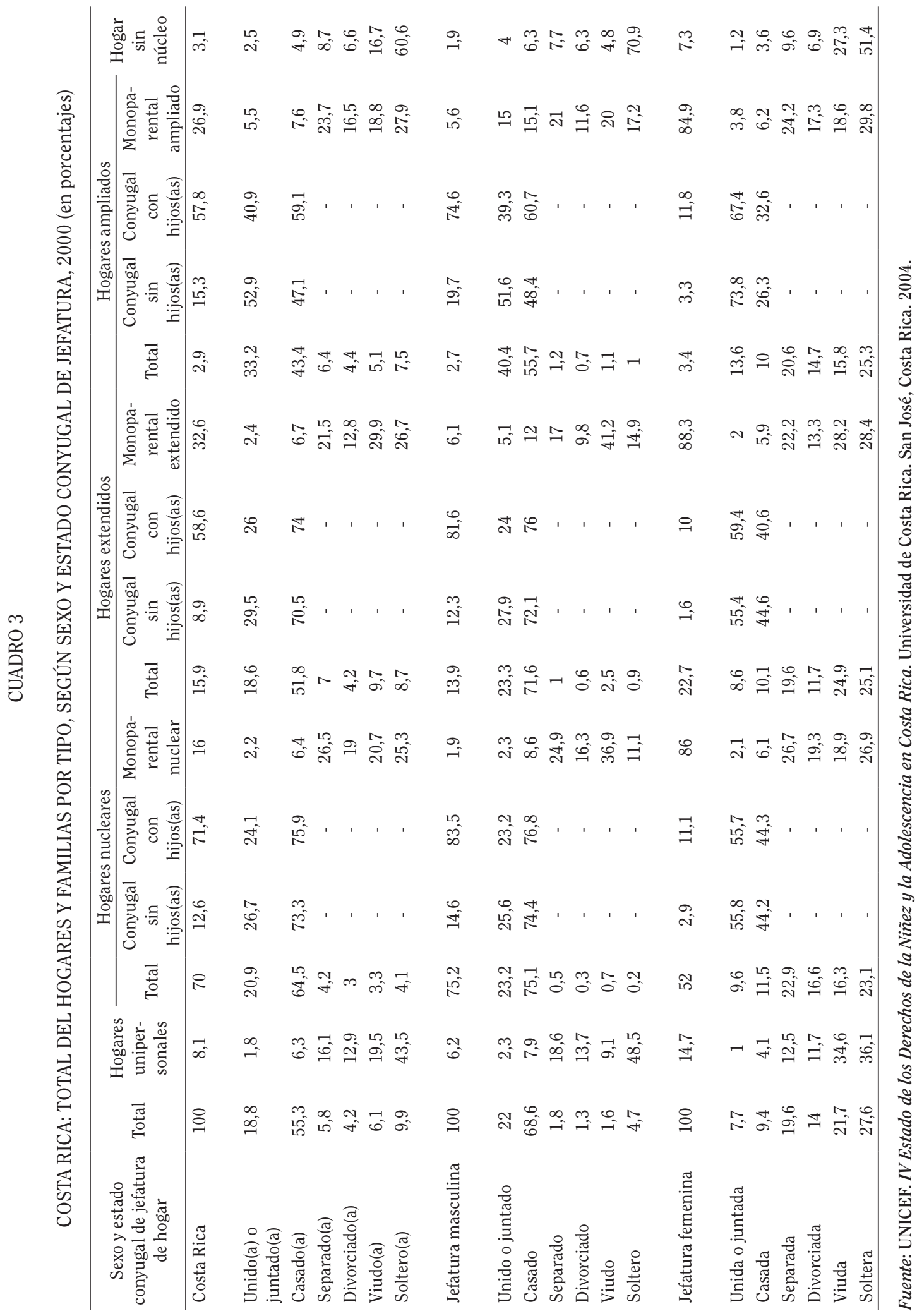


En los cuadros 2 y 3 también se observa el aumento en los divorcios y las separaciones, el cual constituye otra de las variaciones que se han dado en las últimas décadas. Este comportamiento se ha analizado desde dos puntos de vista, uno refleja una visión pesimista, en donde se enfatiza la pérdida de valores, y se evalúa la situación como crisis de la familia (en IDESPO, 2003: citado en UNICEF, 2004). La otra visión considera el divorcio o la separación como una opción más con la que cuentan las personas para continuar con su proceso de desarrollo; enfrentando con realismo las dificultades, diferencias y problemas de la relación de pareja; por tanto, el divorcio forma parte de la lógica del matrimonio, ya no es vista como un sacramento eclesiástico indisoluble (Salles y Tuirán, 1996). Así, las familias con jefatura en condición de divorcio se duplicaron y pasaron de 2,0\% en 1984 a 4,2\% en el 2000. Las jefaturas en condición de separadas también aumentaron de 3,9\% (1984) a 5,8\% (2000) y las jefaturas en condición de casadas, por su parte descendieron de 66,0\% (1984) a 55,2\% (2000), mientras que las familias con jefes $y$ jefas en uniones de hecho aumentaron de $13,5 \%$ a un $18,7 \%$ (respectivamente). Por otra parte, las jefaturas en condición de soltería tuvieron un pequeño aumento de 8,5\% (1984) a un 9,8\% (2000).

En los hogares monoparentales disminuyeron las familias con jefatura femenina con jefas solteras de un 29,4\% a 26,9\% entre 1984 $y$ el 2000. Mientras que las familias de jefas $y$ divorciadas y separadas aumentaron de un $34,4 \%$ a un $46,0 \%$ (1984 y 2000, respectivamente). Otro aumento significativo, que llama la atención es el de las familias con jefes divorciados y separados que va de un $22,8 \%$ (1984) a un 41,2\% (2000), así como el de los jefes solteros que aunque más leve, no deja de ser importante de señalarse, pues pasó de un 9,3\% en 1984 a un $11,1 \%$ en el 2000.

En general, de los aspectos analizados en este apartado se desprende que la familia, es el espacio que crea la pareja a partir de su convivencia - sea física y/o amorosa, que implica un compromiso mutuo legalizado o no legalizado, en donde existe distintos niveles del mismo, según la pareja, las personas, sus deseos, intereses, necesidades y valores. La constitución de las familias y sus características va de un "modelo único nuclear" a la diversificación producto de prácticas sociales que responden a nuevas necesidades. Sin embargo, los cambios no invalidan su función social en el tanto continúa siendo una institución social importante en la organización y las relaciones de género, en su interior persisten poderes y jerarquías. También continúa cumpliendo con funciones económicas, socializadoras e ideológicas.

La familia o la unidad doméstica históricamente ha sido un espacio "privado" que ha recreado relaciones de desigualdad y asimetrías entre los géneros, a pesar de su composición heterogénea actual, las inequidades persisten, los cambios obedecen más a procesos micro sociales -importantes - pero no que despuntan al nivel social, sin embargo, crea dificultades $y$ contradicciones cotidianas que hay que resolver, producto de las transformaciones señaladas a lo largo de este artículo.

La unidad doméstica o la familia al ser un ámbito social, cultural e históricamente situado de interacciones $y$ de organización de procesos de reproducción económica, cotidiana $y$ generacional, refleja las estructuras y discursos de poder existentes, la familia es por tanto un espacio desde donde podemos observar lo individual y lo social. Es un espacio en el que se generan interrelaciones materiales, simbólicas $y$ afectivas en donde tiene lugar la formación y socialización primaria de las personas y el reforzamiento de las actividades grupales.

La familia representa un ámbito de prácticas sociales en el que se crean y recrean formas particulares de relaciones sociales, es un espacio dinámico en el que cotidianamente se enfrentan fuerzas opuestas en el tanto existe poder, autoridad, solidaridad y conflictos.

De acuerdo con el marco general presentado, debemos partir de que las familias están en transformación y que dichos cambios se han generado en parte por factores económicos (crisis, ajuste estructural, globalización y participación de las mujeres en el mercado laboral) como sociales (nos referimos a cambios importantes demográficos, educativos, culturales entre otros). A su vez, hay prácticas que hombres y mujeres han incorporado en su cotidianidad inciden en aspectos propios de la identidad de 
género masculina $y$ femenina, $y$ que replantean los vínculos asimétricos y de subordinación a lo interno de las estructuras familiares.

\section{REFLEXIÓN FINAL}

Notamos en general que de alguna manera los cambios que se generan en la identidad de género suelen tener repercusiones importantes en la conformación de las relaciones intrafamiliares. Las transformaciones son complejas y se relacionan con aspectos sociales, económicos, culturales y simbólicos.

Por otra parte, la legalidad o ilegalidad de la unión de la pareja deja de ser importante, simbólicamente tiene más relevancia el grado de compromiso con que cada integrante asume su relación, razón por la cual existen relaciones de pareja que se asumen con un alto grado de compromiso, en donde es posible encontrar a su vez una relación de poder más simétrica.

Cada vez se da una mayor diversificación en la constitución de las parejas. Al respecto podemos destacar algunas experiencias que aunque minoritarias son significativas como exponentes de nuevas tendencias llamadas "parejas contraculturales" que remiten a relaciones no tradicionales como son las uniones internacionales, los matrimonios sin convivencia y el matrimonio homosexual; que complejizan la heterogeneidad de los aspectos que se han venido señalando a lo largo del artículo (Burin y Meler, 1998) ${ }^{15}$.

15 Meler y Burin (1998) señalan al menos tres expresiones de uniones que tienen un peso cada vez mayor en el contexto actual como son: los matrimonios sin convivencia; corresponden a segundas o terceras uniones en donde se conserva el proceso de individuación. En este caso cada uno de los integrantes de la pareja conservan su habitat. De esta forma no alteran los ritmos de vida, ni el estilo. En este caso priva la seguridad emocional derivada del compromiso recíproco a la convivencia cotidiana. Las uniones internacionales; estas uniones se han hecho más factibles en la medida en que existen mejores medios de comunicación que facilitan la relación de pareja. En estos casos uno u otro integrante de la pareja se desplaza periódicamente, son relaciones prolongadas muy propias de los $90 \mathrm{~s}$ e inicios del siglo XXI. El matrimonio homosexual;
Por otra parte, en este artículo hemos identificado los distintos tipos de familias. La práctica cuestiona la familia ideal de la sociedad industrial, razón por la cual podemos hablar de un proceso de transformación en las familias y no de desaparición de esta como institución social, tal como lo han considerado algunos autores $y$ autoras. Las familias se transforman, para dar respuesta a nuevas necesidades que surgen del contexto social particular en el que se desarrolla. Evidentemente, uno de los aspectos que aparece como pivote de cambio es la participación de las mujeres en esferas que antes se consideraban propias de los varones como la integración creciente en el mercado de trabajo, participación política y organizativa, participación en espacios de poder tanto políticos como sociales, así como un mayor acceso y control sobre recursos económicos y materiales en general. Así que, aunque la estructura organizativa siga siendo la misma, la dinámica al interior de las familias tiende a generar nuevos procesos, donde se da una destradicionalización de las relaciones de pareja y de las familias. Lo que hace complejas las dinámicas, pues hay una mayor presencia de los intereses y necesidades individuales $y$, muy heterogéneas las experiencias, que están siendo impactadas por aspectos sociales, económicos, culturales, espaciales y geográficos y viceversa.

\section{BIBLIOGRAFÍA}

Ariza, Marina y Oliveira, Orlandina (documento inédito). "Familias en transición y marcos conceptuales en redefinición”. 2001.

es una forma de unión parental que ha ido ganando aceptación lentamente en nuestra sociedad. A pesar de que la homosexualidad ha existido históricamente, tal cual nos lo ha evidenciado Foucault (1986) en sus trabajos sobre "Historia de la sexualidad", la convivencia homosexual, no ha sido un fenómeno social. Sin embargo, actualmente, como parte de los espacios y reivindicaciones que el movimiento gay ha ido ganando, algunos países desarrollados han legalizado estos vínculos, y es posible que tal práctica se extienda paulatinamente. 
Arriagada, Irma. "Familias en un contexto de modernidad". En: Cambio de las familias en el marco de las transformaciones globales: necesidad de politicas públicas eficaces. Chile, CEPAL, UNFPA y Naciones Unidas. 2004.

"Políticas sociales, familia y trabajo en la América Latina de fin de siglo". Chile, CEPAL, Serie Politicas Sociales. 1997. Núm. 21.

Batres y Claramunt. Violencia contra la mujer en la familia costarricense. San José: Asociación Demográfica Costarricense. 1993.

Beck, Ulrich y Elisabeth Beck Gernsheim. El normal caos del amor. Las nuevas formas de la relación amorosa. Barcelona. Paidós. 2001.

Benhabib, Seyla. "Desde las políticas de identidad al feminismo social: un alegato para los noventa". En: Las ciudadanas y lo político. Madrid. Instituto Universitario de Estudios de la Mujer. 1996.

Burin, Mabel y Meler, Irene. Género y familia, poder, amor y sexualidad en la construcción de la subjetividad. Buenos Aires, Barcelona y México. Paidós. 1998.

género y subjetividad masculina. Argentina. Ed. Paidós, Psicología Profunda. 2000.

CEPAL. Cambio de las familias en el marco de las transformaciones globales: necesidad de políticas públicas eficaces. Chile, CEPAL, UNFPA y Naciones Unidas. 2004.

la familia en América y el Caribe". En: Familia y futuro, un programa regional en América Latina y el Caribe. Santiago de Chile, UNICEF. 1994, pp.19-36.

Centro Nacional para el Desarrollo de la Mujer y la Familia. Situación de las mujeres en
Costa Rica: 1985-1994. San José, Costa Rica. CMF. 1995.

Céspedes, Víctor H. y Jiménez, Ronulfo. La pobreza en Costa Rica: concepto, medición, evolución. San José, Costa Rica. Academia de Centro América. 1995.

Claramunt, $\mathrm{M}^{\mathrm{a}}$ Cecilia. Casitas quebradas. El problema de la violencia doméstica en Costa Rica. San José, Costa Rica. EUNED. 1997.

Cohen, Theodore. "Fathering and Providing". En: Hood, Jane (ed.) Men, Work and Family. Londres. Sage Publications. 1993, pp. 1-22.

Concha, José Miguel. "Crisis económica, mercado de trabajo y precariedad laboral". En: Acta Sociológica núm. 7, enero-abril. 1993, pp. 23-37.

Cordero, Allen. "La base social y política de la familia". En: Realidad familiar en Costa Rica. San José. FlACSO, UNICEF. Instituto de Investigaciones Psicológicas de la Universidad de Costa Rica. 2001.

De Barbieri, Teresita. "Sobre géneros, prácticas $y$ valores: notas acerca de posibles erosiones del machismo en México". En: Juan Manuel Ramírez Sáiz (coord.), Normas y prácticas morales y cívicas en la vida cotidiana. México, UNAM/CIIH. 1990, pp. 83-105.

Mujeres y vida cotidiana. México. Fondo de Cultura Económica e Instituto de Investigaciones Sociales-UNAM. 1984.

Díaz, Capitolina, et al. Estudio de las relaciones de género y poder en los procesos de toma de decisiones en el ámbito privado. Una comparación internacional de las relaciones de pareja. Madrid. Ministerio de Trabajo y Asuntos Sociales, Instituto de la Mujer. 2004. 
Faune, María Angélica. "Cambios en las familias en Centroamérica”. En: Familias Siglo XXI. Chile ISIS Internacional. 1994.

Feijoo Ma del Carmen y Cogna Mónica. "Las mujeres en la transición a la democracia”. En: Jelin, Elizabeth. Participación, ciudadanía e identidad, las mujeres en los movimientos latinoamericanos. Ginebra. UNRISD. 1987.

FLACSO. Mujeres Latinoamericanas en cifras: Costa Rica. Madrid. Instituto de la Mujer de Madrid y Flacso Chile. 1993.

Freud, Sigmund (1913). "Tótem y tabú". En: Obras Completas. Buenos Aires, Amorrortu. 1980.

Foucault, Michel. Historia de la sexualidad, la voluntad de saber. Tomo I, $27^{\text {a }}$ edición. Siglo XXI. México. 1999.

García, Brígida; de Oliveira, Orlandina. Trabajo femenino y vida familiar en México. México, El Colegio de México. 1994.

. "Family Dinamics and Urban Poverty: A Mexican and Latin American perspective". Paper presented at the Seminar on Demography and Poverty. Florence, Italy. 1995.

. "La dinámica familiar en la Ciudad de México y Monterrey". En: Informe final del proyecto: Trabajo, familia y empoderamiento de las Mujeres en México. El Colegio de México. México. 2000.

. "Cambios socio-económicos y división del trabajo en las familias mexicanas". En: Revista de Investigaciones Económicas. Vol. LXI: 236, abril-junio de 2001, pp. 137-162.

Garnier, Leonardo. Costa Rica, entre la ilusión y la desesperanza. San José, Costa Rica. Ediciones Guayacán. 1991.
González de la Rocha, Mercedes. "Los límites de las estrategias de sobrevivencia: Viejos y nuevos enfoques para el análisis de las respuestas familiares y domésticas". Trabajo presentado en el Latin America Labor and Globalization Trends Following a Decade of Economic Adjustment: a Worshop, organizado por el SSRC y FLACSO. Costa Rica. 2000.

Gudmundson, Lowell. Costa Rica antes del café. Costa Rica. Editorial Universidad de Costa Rica. 1986.

Gudman, Matthew. "Los hombres cambiantes, los machos impenitentes y las relaciones de género en México en los noventa". En: Estudios Sociológicos. Vol. XI, núm. 33, septiembre-diciembre, 1993, pp. 725-740.

Guzmán, Laura. "Los estudios sobre la familia en Costa Rica: una mirada crítica desde los estudios de la mujer". En: Vega y Cordero (Editores). Realidad familiar en Costa Rica. Costa Rica. UNICEF, FLACSO y IIP-UCR. 2001.

. "Relaciones de género y estructuras familiares". En: Revista Costarricense de Trabajo Social. 1994, 4:4, pp. 17.

Giddens, Anthony. La transformación de la intimidad: sexualidad, amor y erotismo en las sociedades modernas. Madrid. Ediciones Cátedra. 1995.

. La constitución de la sociedad, bases para la teoría de la estructuración. Argentina. Amorrortu Editores. 1981.

Harenven, Tamara. "A complex relationship: family strategies and the processes of economic and social change". En: Roger Friedland y A. F. Robertson (eds.) Beyond the market place, rethinking economy and society. New York. Aldine de Gruyter. 1990. 
Hernández Zinzún, Sergio. "Estrategias familiares $y$ poder marital, un estudio en parejas conyugales de sectores medios y populares de Tijuana, México". Borrador de tesis para ser sometido a la consideración del Doctorado en Ciencia Social con Especialidad en Sociología, del Centro de Estudios Sociológicos. El Colegio de México. 2001.

Harenven, Tamara y Kanji, Ma saoka. "Turning points and transitions: perceptions of the life course". En: Journal of family history. 1988, vol. 13, núm. 3, pp 271-289.

Hernández Zinzún, Sergio. "Estrategias familiares $y$ poder marital, un estudio en parejas conyugales de sectores medios $y$ populares de Tijuana, México". Borrador de tesis para ser sometido a la consideración del Doctorado en Ciencia Social con Especialidad en Sociología, del Centro de Estudios Sociológicos, El Colegio de México. 2001.

Jameson, Fredric. El giro cultural. Buenos Aires. Manantial. 1999.

Jelin, Elizabeth. "Relaciones intrafamiliares en América Latina”. En: Familia y Futuro. Un programa regional en América Latina y el Caribe. Santiago de Chile. CEPAL, UNICEF. 1994, pp. 37-55.

Pan y afectos, transformación de las familias. México. Fondo de Cultura Económica. 1998.

Levi-Strauss, Claude. The Elementary Structures of kinship. London. Eyre \& Spottiswoode. 1969.

Lungo, Mario; Pérez, Mariam y Piedra, Nancy. "La urbanización en Costa Rica en los 80". En: Alejandro Portes y Mario Lungo (coordinadores). Urbanización en Centro América. San José. FLACSO. 1992.

Lyotard, JeanFrançois. La posmodernidad (explicada para niños). Barcelona. Gesida Editorial. 1992.
Maffesoñi, Michel. El instante eterno. El retorno de lo trágico en las sociedades posmodernas. Buenos Aires, Barcelona, México. Paidós. 2000.

MIDEPLAN. Imágenes de género: estadísticas sociodemográficas y económicas desagregadas por sexo. Costa Rica 1980-1994. San José. MIDEPLAN. 1995.

- Costa Rica: balance del ajuste estructural: 1985-1991. Ministerio de Planificación Nacional y Política Económica. San José, Costa Rica. 1993.

Morgan, D.H.J. Social theory and the family. London, Boston y Henley, Routledge \& Kegan Paul. 1975.

Oliveira, Orlandina. "Familias y relaciones de género en México". En: Schmuker, Beatriz (coord.), Familias y relaciones de género en transformación. México. Populatión Council-Edemax. 1998a, pp. 23-52.

- "Experiencias matrimoniales en México: la importancia de la familia de origen". En: Vida familiar y cultura contemporánea. México. Pensar la Cultura. 1998b.

. "Transformaciones socioeconómicas, familia y condición femenina. Versión ampliada del trabajo "Cambios socioeconómicos y condición femenina” preparado en el taller The Americas Program: Demographic and Health Outcomes of Economic Integration". Organizado por el Pacific Institute for women's Health del 21 al 24 de febrero de 1996. Versión ampliada. 1999.

. "Familia y relaciones de género" Ponencia presentada en VIII Simposium Internacional sobre Mujer, familia y sociedad, organizado por la Sociedad Internacional de Pro-valores Humanos. 
México, E. From-S. Zubirán A.C., marzo 22-23. 1995.

. "Presencias y ausencias femeninas". En: Trabajo poder y sexualidad. México. El Colegio de México. 1991.

Oliveira, Orlandina y Gómez, M. "Subordinación y resistencia femeninas: notas de lecturas". En: Trabajo, poder y sexualidad. México. El Colegio de México. 1989.

Oliveira, Orlandina; Ariza, Marina; Eternod, Marcela. "La fuerza de trabajo en México: un siglo de cambios" (versión preliminar). En: Proyecto: Cien años de democracia en México. Fondo de Cultura Económica. 1998. (en prensa).

Oliveira, O.; Ariza, M. et al. Informe final, La condición femenina: una propuesta de indicadores. México. SOMEDE-CONAPO. 1996.

Perlman, Daniel. "Copules career orientation, Gender, role orientation, and percived equity as determinants of marital power. En: Journal of Marriage and the Family. 1989, vol. 51: 993-41.

Pizarro, Roberto. "La vulnerabilidad social $y$ sus desafíos: una mirada desde América Latina”. En: CEPAL, Serie de Estudios Estadísticos y Prospectivos. 2001, núm.6.

Programa Estado de la Nación. Décimo Informe Estado de la Nación en Desarrollo Humano Sostenible. San José, Costa Rica. 2004.

Reuben, Sergio. "Estructura familiar en Costa Rica”. En: Avances de Investigación, núm. 57. Costa Rica, Universidad de Costa Rica, Instituto de Investigaciones Sociales. 1986.

Rojas, Olga L. "Paternidad y vida familiar en México: un acercamiento cualitativo al papel desempeñado por los varones en los ámbitos reproductivos y domésticos". Tesis presentada para optar al grado de Doctorado en Población. En: El Centro de Estudios Demográficos y de Desarrollo Urbano. El Colegio de México. 2000.

Roldán, Marta. "Pautas de control del circuito monetario doméstico y formas de conciencia entre trabajadoras industriales domiciliarias en la ciudad de México". Ponencia presentada en la reunión de Investigación sobre Mujer e investigación feminista: balances y perspectivas de la década de la mujer en América Latina, Montevideo, GRECMU, 8 al 11 de diciembre. 1984. (mimeografiado).

Rodríguez, Eugenia. "Reformando y secularizando el matrimonio. Divorcio, violencia doméstica y relaciones de género en Costa Rica (1850-1950)”. En: Gonzalbo, Pilar. Familias Iberoamericanas: historia, identidad y conflicto. México. El Colegio de México. Centro de Estudios Históricos. 2001.

. Hijas, novias y esposas. Familia, matrimonio y violencia doméstica en el Valle Central de Costa Rica 1750-1850. Heredia, CR. EUNA. 2000.

(coord.). "Civilizando la vida doméstica en el Valle Central de Costa Rica. (1750-1850)". En: Entre silencios y voces (1750-1990). 1ed. San José, CR. Centro Nacional para el Desarrollo de la Mujer y la Familia. 1997.

Rovira, Jorge. Costa Rica en los años 80. San José, Costa Rica. Editorial Porvenir. 1987.

Ruiz, Keynor. "Mercado de Trabajo y Feminización de la pobreza". Mimeo. Presentado en el Seminario: Mujeres, pobreza y política social. CMF, IDEAS. 1996.

Sagot, Monserrat. "Women political activism and housing: the case of women's struggle 
for housing in Costa Rica". Dissertation Doctoral, The American University, Washington, DC. 1991.

"The struggle for husing in Costa Rica: the transformation of women into political actors". En: (Ilse Abshagen Leitinger, compiladora). The Costa Rican women's movement. University of Pittsburgh Press, Pittsburgh. 1987.

Salvia, Agustín. "La familia y sus desafíos de su objetivación: enfoques y conceptos". En: Estudios Sociológicos. 1995, vol. 13, núm. 37, enero-abril, pp. 143-162.

Salles, Vania. "Las familias, las culturas, las identidades (notas de trabajo para motivar una discusión)". En: Vida familiar y cultura contemporánea. México. Pensar la Cultura. 1998a.

"Sociología de la cultura, relaciones de género y feminismo: una revisión de aporte". México: El Colegio de México, Centro de Estudios Sociológicos. Ponencia presentada a CONAPO. 1998 b.

"Hogares de la frontera". En: Nueva Antropología, núm. 46. México. 1993.

. "Cuando hablamos de familia: ¿de qué familia estamos hablando?". En: Nueva Antropología. 1991, núm. 39, vol. 10. México, junio.

Salles, Vania y Tuirán, Rodolfo. "Mitos y creencias sobre la vida familiar". En: Revista Mexicana de Sociología. 1996. Año LVIII, vol. 2.

Sojo, Ana. Mujer y política: ensayo sobre el feminismo y el sujeto popular. San José, Costa Rica. DEI. 1985.

Trejos, Juan Diego. "Empleo, distribución del ingreso y pobreza durante los inicios del ajuste en Costa Rica.1987-1992”. IICE,
UCR. Documentos de trabajo, 1995a, núm. 173.

. "La pobreza en Costa Rica: una síntesis cuantitativa". IICE, UCR. Documentos de trabajo, 1995b, núm.172.

UNICEF, PRIDENA, Universidad de Costa Rica. IV Estado de los derechos de la niñez y la adolescencia en Costa Rica. San José, Costa Rica. 2004.

Valdés, Teresa y Gomáriz, Enrique. Mujeres latinoamericanas en cifras: Costa Rica. Chile. Instituto de la Mujer y FLACSO Chile. 1993.

Valdés, Teresa; Gysling, Jacqueline y Benavente, $\mathrm{M}^{\mathrm{a}}$ Cristina. El poder en la pareja, la sexualidad y la reproducción. Santiago, Chile. FLACSO-Chile. 1999.

Vega, Isabel (1996). "La familia costarricense en las postrimerías del siglo XX: ¿Se desintegra o se transforma?". Revista Parlamentaria. 1996, vol. 4, nro. 3, diciembre.

"Las familias costarricenses en el contexto del nuevo milenio" En: Realidad familiar en Costa Rica. San José. FLACSO, UNICEF, Instituto de Investigaciones Psicológicas de la Universidad de Costa Rica. 2001.

. "Consideraciones en torno a la investigación sobre familia: retos prioridades" En: Realidad familiar en Costa Rica. San José. FLACSO, UNICEF, Instituto de Investigaciones Psicológicas de la Universidad de Costa Rica. 2001.

(compiladora). Pareja y familia en la sociedad actual: ¿nuevos significados y desafíos? Costa Rica, Universidad de Costa Rica. 2003a.

. El divorcio y las nuevas dimensiones de la paternidad. Costa Rica, Universidad de Costa Rica. 2003b. 
(1985) "Tendencias en los estudios sobre familia: Costa Rica 1990-1995”. En: Actualidades en Psicología. Instituto de Investigaciones Psicológicas, Facultad de Ciencias Sociales, Universidad de Costa Rica. 1999. Volumen 1, núm. 1. San José, Costa Rica.

. "Diversidad familiar en Costa Rica, un análisis tipológico en la Región Metropolitana”. En: Actualidades en Psicología. 1994. Volumen 9, núm. 79. Programa de Psicología Social, Instituto de Investigaciones Psicológicas, UCR, Costa Rica.
"Cambio social, estructura y dinámica familiar en Costa Rica”. Tesis de doctorado. Universidad Complutense de Madrid, Facultad de Psicología, Departamento de Psicología Social. 1993.

Vega, Isabel y Cordero, Allen. Realidad familiar en Costa Rica. Costa Rica. UNICEF, FLACSO Sede Costa Rica y Universidad de Costa Rica. 2001.

Yanagisako, Silvia Junko."Family and Household: the analysis of domestic groups". En: Annual Review of Anthropology. 1979, núm. 8, pp. 161-204. 